\title{
Fenologia e Acúmulo de Matéria Seca em Plantas de Murdannia nudiflora DURANTE SEU CIClO DE VIDA ${ }^{1}$
}

\author{
Phenology and Accumulated Dry Matter Accumulation in Murdannia nudiflora Along its \\ Life Cycle
}

ERASMO, E.A.L. ${ }^{2}$, TERRA, M.A. ${ }^{3}$, COSTA, N.V. ${ }^{3}$, DOMINGOS, V.D. ${ }^{3}$ e DIDONET, J. ${ }^{2}$

RESUMO - Este trabalho objetivou estudar a fenologia e o acúmulo de matéria seca ao longo do ciclo de vida de Murdannia nudiflora, visando conhecer seu potencial de crescimento. Para isso, sementes dessa espécie daninha foram semeadas em canteiros (5,0 x 3,0 x 0,2 m), cujo substrato constituiu-se de solo de várzea proveniente de áreas de cultivo de arroz irrigado. Os tratamentos constituíram-se de 11 épocas de colheita das plantas $(10,20,30,40,50,60$, $70,80,90,100$ e 110 dias após a emergência - DAE). No final de cada época, seis plantas foram colhidas e separadas nos seus componentes vegetativos (pseudocaule, estolão, raiz e folha), determinando-se em seguida a matéria seca. O desenvolvimento do pseudocaule durante todo o ciclo aumentou linearmente. O maior acúmulo de matéria seca total, nas raizes e folhas, ocorreu entre os períodos de 20 a 80 DAE, apresentando ajuste quadrático. A partir dos 80 DAE, observou-se acúmulo de matéria seca de 59\% nos estolões, 31,7 e 9,3\% nas folhas e raízes, respectivamente, em relação àquele verificado na planta-mãe. A formação das "plantas-filhas" ocorreu a partir dos 40 DAE; a partir do pico de produção de matéria seca (aos 80 DAE), estas atingiram, em média, $84,8 \%$ da matéria seca total da planta. O acúmulo de matéria seca nas plantas-filhas foi semelhante ao verificado na planta-mãe. Naquela, houve tendência de o acúmulo manter-se constante após o ponto máximo de produção.

Palavras-chave: crescimento, Commelinaceae, planta daninha.

\begin{abstract}
This work aimed to study the phenology and accumulation of dry matter of Murdannia nudiflora along its life cycle to determine its growth potential. Seeds were sown in $5.0 \times 3.0 \times 0.2 \mathrm{~m}$ in substrates from lowland soil from irrigated-rice cultivated areas. Treatments consisted of 11 different plant harvesting times (10,20, 30, 40, 50, 60, 70, 80, 90, 100 and110 days after emergence) with 6 plants being harvested per time and divided into the following components: Pseudostem, roots and leaves followed by dry matter determination. Pseudo stem development increased linearly throughout the cycle. The highest total dry matter accumulation in the roots and leaves occurred between 20 and 80 DAE, presenting quadratic adjustment. After $80 \mathrm{DAE}, 59 \%, 31.7 \%$ and 9.3\% dry matter accumulation was observed in the stolons, leaves and roots, respectively, compared to the parent-plant. Daughter-plant formation was found to occur after $40 \mathrm{DAE}$, with dry matter production reaching an average of $84.8 \%$ of the total plant dry matter, after peak production (80 DAE). Dry matter accumulation in the parent-plant was similar to that in the daughter-plants, with the latter's tending to remain constant after peak production.
\end{abstract}

Key words: plant growth, commelinaceae, weed.

Recebido para publicação em 4.4.2003 e na forma revisada em 12.12.2003.

2 Eng.-Agr. Dr. Professor da Fundação Universidade do Tocantins - UNITINS, campus de Gurupi, Caixa Postal 66, 77400-000 Gurupi-TO, <erasmolemus@uol.com.br>. ${ }^{3}$ Eng.-Agr., aluno do Curso de Pós-Graduação da FCA-UNESP, <neumarcio@fca.unesp.br>, Caixa Postal 237, 18603-970 Botucatu-SP. 


\section{INTRODUÇÃO}

Em algumas regiões produtoras de arroz irrigado ao sul do Estado do Tocantins, temse verificado o surgimento de uma espécie de planta daninha pertencente à família Commelinaceae, que tem crescido em importância devido à sua rápida expansão nas áreas de produção, ao elevado poder competitivo com a cultura e a dificuldades encontradas no seu controle. Essa espécie, identificada como Murdannia nudiflora, é de porte rasteiro, com formação de caules estoloníferos, e possui dispersão via sementes (Kissmann \& Groth, 1997). Poucas são as informações existentes na literatura nacional sobre essa espécie. Estudos sobre o crescimento e o desenvolvimento das plantas permitem obter importantes informações sobre as fases fenológicas e padrões de crescimento, fornecendo, assim, subsídios para análise tanto do comportamento dessas plantas diante de fatores ecológicos, como de sua ação sobre o ambiente, especialmente de sua interferência sobre outras plantas (Lucchesi, 1984).

As plantas daninhas são um dos principais fatores que limitam a obtenção do máximo potencial produtivo das lavouras de arroz irrigado (Amaral, 1995). O balanço competitivo entre as comunidades infestantes e as culturas agrícolas depende de fatores relacionados à própria comunidade infestante (composição específica, densidade e distribuição), à cultura (espécie ou variedade, espaçamento e densidade de plantio), bem como à extensão do periodo de convivência, podendo esses fatores ser alterados pelas condições edafoclimáticas e pelos tratos culturais (Pitelli, 1985). A queda na produção de grãos, devido à competição exercida pelas plantas daninhas sobre a cultura do arroz, varia de 9,1 a 59,5\%, sendo essa variação seguramente relacionada às diferenças entre espécies, população, período de competição, hábitos de crescimento e vigor das plantas, que ocorrem entre regiões (Barros \& Porto, 1979). Espécies como Cyperus esculentus e Echinochloa crusgalli, quando convivem com a cultura de arroz irrigado, reduzem o rendimento de grãos em 38,5 a 80\% (Andrade, 1992; Smith, 1983; Amaral, 1995).

Uma das limitações que tornam ineficiente um programa de manejo integrado é a falta de conhecimento sobre a biologia e ecologia das plantas daninhas. A investigação básica pode prover informações necessárias sobre as razões da presença das plantas daninhas, contribuindo para o desenvolvimento de estratégias adequadas para seu controle (Fernandez, 1982).

Dessa maneira, objetivou-se com este trabalho identificar os diferentes estágios fenológicos de $M$. nudiflora e o acúmulo de matéria seca durante seu ciclo de vida, a fim de contribuir com subsídios que auxiliem nas tomadas de decisão sobre o manejo dessa espécie daninha na cultura do arroz irrigado.

\section{MATERIAL E MÉTODOS}

Este trabalho foi instalado na estação experimental da Universidade do TocantinsUNITINS, no campus da Faculdade de Agronomia, no município de Gurupi, localizado a $11^{\circ} 43^{\prime} 45^{\prime \prime} \mathrm{S}, 4^{\circ} 04^{\prime} 07^{\prime \prime} \mathrm{N}$ e a $280 \mathrm{~m}$ de altitude. O experimento foi conduzido em dois canteiros de $5 \mathrm{~m}$ de comprimento por $3 \mathrm{~m}$ de largura e $0,2 \mathrm{~m}$ de altura, cujo substrato constituiu-se de solo de várzea, coletado em áreas de produção de arroz irrigado, isento de qualquer resíduo de herbicidas.

O delineamento experimental utilizado foi o inteiramente casualizado, com 11 tratamentos e seis repetições. Os tratamentos constituíram-se de 11 épocas de colheita das plantas daninhas, realizadas em intervalos de 10 dias, iniciando-se aos 10 dias após a emergência (DAE). Para promover a quebra da dormência, as sementes de $M$. nudiflora foram tratadas com ácido sulfúrico (absoluto), por um período de 30 s. Em seguida, procedeu-se à semeadura de forma a se obter uma densidade populacional de 60 plantas por canteiro, espaçadas a $0,5 \mathrm{~m}$ entre si.

A fenologia da espécie foi descrita relacionando-se as alterações morfológicas ao número de dias após a emergência das plântulas. Foram consideradas plantas-filhas aquelas que surgiram nos nós dos caules estoloníferos oriundos da primeira planta formada (plantamãe). Em cada época de coleta, foram avaliados o número médio de folhas e de plantas filhas por planta e o comprimento médio dos estolões. Este último foi determinado pela soma das medições dos estolões primários e secundários produzidos pela planta. 
Para avaliar o acúmulo de matéria seca, no final de cada época, seis plantas (três por canteiro) foram colhidas e separadas nos seus componentes vegetativos (raízes, estolões e folhas) e colocadas em estufa de circulação forçada de ar, a $70{ }^{\circ} \mathrm{C}$, até atingir massa constante. Em seguida, em cada tratamento, determinou-se a massa de matéria seca total e de cada componente vegetativo.

Após a transformação dos dados para ln $(x+a)$, foram ajustadas equações de regressão relacionando a matéria seca com a época de coleta. Foram escolhidos modelos significativos, com lógica biológica e de elevado $\mathrm{R}^{2}$.

\section{RESULTADOS E DISCUSSÃO}

A emergência de todas as plântulas ocorreu aos quatro dias após a semeadura (DAE), sendo estas compostas por folhas pequenas, originadas de um pseudocaule formado pelo entumescimento de várias gemas foliares. Como essa espécie forma caules estoloníferos, as fases vegetativas e reprodutivas não foram definidas exatamente, variando conforme a idade de surgimento das plantas-filhas produzidas (Figura 1).

Nos primeiros 30 DAE, a espécie $M$. nudiflora apresentou crescimento lento e investiu na produção de folhas e raízes. A partir dessa data iniciou-se a emissão de ramificações na forma de caules estoloníferos que se originaram do ponto de inserção da primeira folha da planta-mãe (Tabela 1). Aos $40 \mathrm{DAE}$, a planta apresentava, em média, nove folhas e três plantas-filhas, e os estolões mediam $1,9 \mathrm{~cm}$ de comprimento. Os caules estoloniferos apresentaram comprimento entre 1,9 e $49 \mathrm{~cm}$ aos $40 \mathrm{e}$ 110 DAE, respectivamente, com um ou dois nós. Aos 60 DAE, com aproximadamente $8,4 \mathrm{~cm}$, alguns caules estoloniferos iniciaram a emissão de caules estoloníferos secundários. Nessa fase, os nós que estavam em contato com o solo emitiam pequenas raízes, que serviriam, possivelmente, tanto para a fixação da planta como para absorção de água e nutrientes do solo.

Nas terminações de cada caule estolonífero e também da planta-mãe, houve uma bifurcação, de onde se originaram duas hastes, que

Tabela 1 - Número médio de folhas (NMFO) e de plantasfilhas (NMPF) por planta e comprimento médio de estolões (CME) de M. nudiflora

\begin{tabular}{|c|c|c|c|}
\hline $\begin{array}{c}\text { Dias após a } \\
\text { emergência }\end{array}$ & NMFO & NMPF & $\begin{array}{c}\text { CME* } \\
(\mathrm{cm})\end{array}$ \\
\hline 10 & 2,2 & - & - \\
\hline 20 & 2,8 & - & - \\
\hline 30 & 4,2 & - & - \\
\hline 40 & 9,2 & 2,7 & 1,9 \\
\hline 50 & 25,3 & 4,8 & 3,3 \\
\hline 60 & 48,7 & 7,0 & 8,4 \\
\hline 70 & 98,7 & 8,8 & 19,1 \\
\hline 80 & 118,5 & 7,8 & 39,5 \\
\hline 90 & 105,2 & 7,2 & 41,8 \\
\hline 100 & 105,2 & 7,3 & 45,5 \\
\hline 110 & 114,5 & 5,7 & 49,0 \\
\hline
\end{tabular}

* CME - somatório de estolões primários e secundários.

Fase Vegetativa

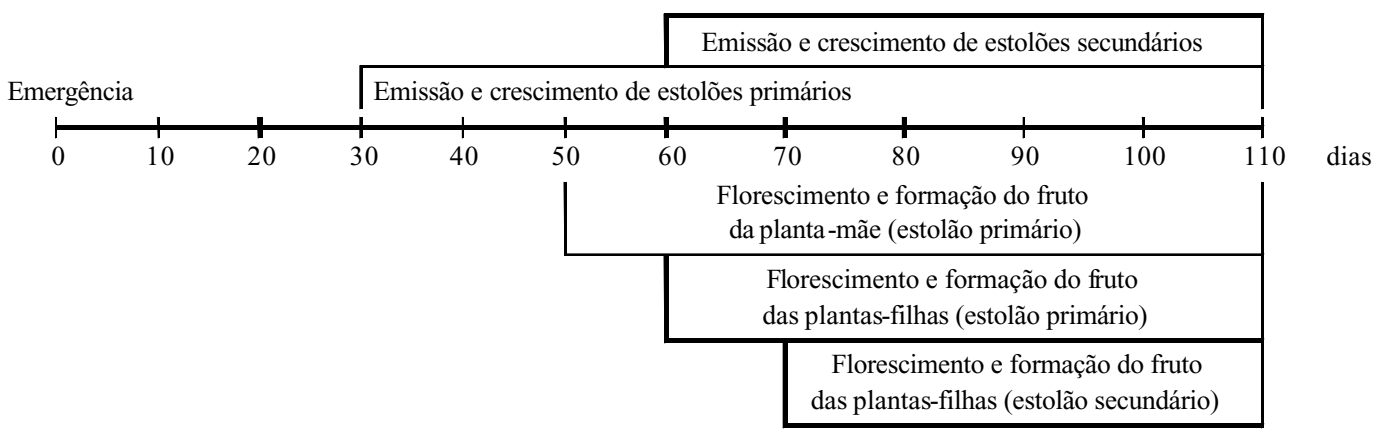

Fase Reprodutiva

Figura 1 - Esquema das fases vegetativa e reprodutiva de $M$. nudiflora, ao longo do seu ciclo de vida. 
serviram de sustentação para as inflorescências. Estas se formaram sobre duas hastes menores, que se desenvolveram no ápice das duas anteriores. Dessa maneira, cada caule estolonífero formou quatro inflorescências.

A floração iniciou-se na planta-mãe aos 50 DAE e, na primeira planta-filha, aos 60 DAE. A formação dos frutos iniciou-se aos quatro dias após a emissão das flores. Os frutos, pequenas cápsulas triloculares, eram agrupados em cachos, cada um com oito cápsulas triloculares. Cada cápsula apresentava cinco sementes.

Como cada caule estolonifero produz quatro inflorescências e cada uma destas origina um cacho com oito frutos, contendo, cada um, cinco sementes, apenas um caule estolonífero apresenta potencial para produzir 160 sementes. Verificou-se que as plantas-filhas apresentam comportamento similar ao observado nas plantas-mães. Assim, é possivel estimar que uma planta adulta, com sete plantas-filhas e cada filha com três filhas secundárias, produzirá, ao longo de seu ciclo de vida, aproximadamente 4.640 sementes.

Verificou-se aumento crescente no número de folhas até $80 \mathrm{DAE}$. Comportamento semelhante foi observado também para o número de plantas-filhas. Dos 40 aos $110 \mathrm{DAE}$, houve aumento progressivo no comprimento médio dos estolões, devido ao surgimento de plantasfilhas secundárias (Tabela 1).

No gráfico referente aos estolões (Figura 2), a matéria seca acumulada aos $30 \mathrm{DAE}$ representa apenas o pseudocaule da plantamãe, porém, nas demais datas, foi incluída, além do pseudocaule, a matéria seca dos estolões das plantas-filhas. Todos os componentes vegetativos da planta evidenciaram um padrão comum de resposta, ajustando-se a curvas de modelo quadráticas. A maior taxa de acúmulo de matéria seca de todos os componentes vegetativos ficou compreendida entre $10 \mathrm{e}$ $80 \mathrm{DAE}$, a partir da qual a curva mostra seu ponto de convexidade. Após esse ponto, há uma redução na massa seca de todos os componentes da planta. Os órgãos que tiveram maior participação nessa redução foram as raízes e as folhas (Figura 2).

Houve decréscimo acentuado na participação das folhas e aumento na participação dos estolões no total de matéria seca acumulada pelas plantas, ao longo do ciclo (Figura 5a). O inverso foi verificado para os estolões. As raizes apresentaram participação mais ou menos constante nos períodos de crescimento compreendidos entre 20 e $60 \mathrm{DAE}$ e de 70 e 110 DAE. Neste último houve menor porcentagem de participação. Observou-se, a partir dos 80 dias de crescimento, menor participação das folhas e raízes no total de matéria seca da planta, correspondendo, em média, a 31,7 e $9,3 \%$, respectivamente; já os estolões representaram $59 \%$ do total acumulado pela planta (Figura 5a).

Nos primeiros $30 \mathrm{DAE}$, a matéria seca total de $M$. nudiflora correspondia somente àquela da planta-mãe. A partir dessa época iniciou-se a formação de plantas-filhas com acúmulo de matéria seca crescente até $70 \mathrm{DAE}$, estabilizando-se a partir dessa época, com participação média de $80 \%$ da matéria seca total nas plantas (Figura 5b).

Para a planta-mãe, com exceção do pseudocaule, o acúmulo de matéria seca ajustou-se a curvas de modelo quadráticas (Figura 3), apresentando comportamento similar ao descrito na Figura 2. O pseudocaule apresentou taxa de crescimento constante, ajustando-se a um modelo de regressão linear. Quando se avaliou a participação desses componentes no total de matéria seca ao longo do ciclo de vida de $M$. nudiflora (Figura 5c), observou-se participação crescente das raízes, principalmente a partir dos $60 \mathrm{DAE}$, na média de $70,7 \%$ do total acumulado. Verificou-se, nos primeiros

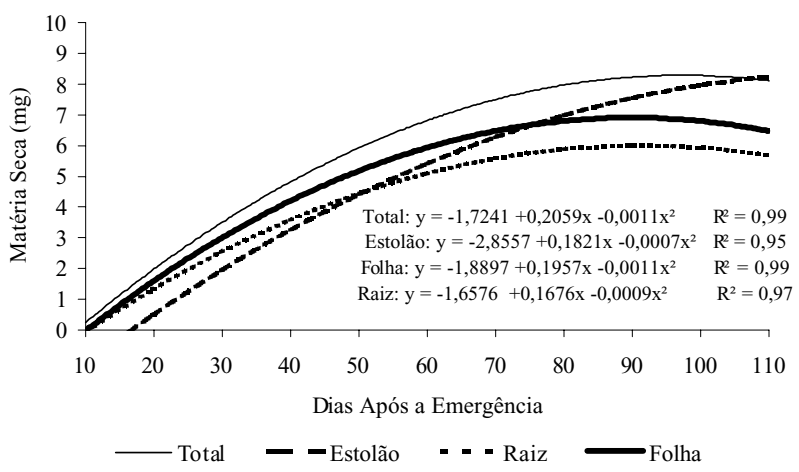

Figura 2 - Acúmulo de matéria seca nos diferentes componentes vegetativos de $M$. nudiflora, ao longo do seu ciclo de vida. 
50 DAE, maior participação das folhas $(58,2 \%$ da matéria seca total). O pseudocaule expressou uma participação constante a partir dos 70 DAE, correspondendo a $20 \%$ da matéria seca total.

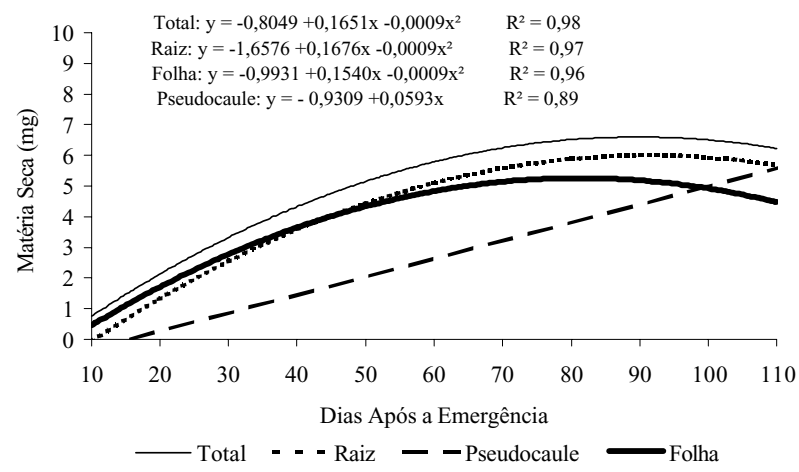

Figura 3 - Acúmulo de matéria seca nos diferentes componentes vegetativos da planta-mãe de $M$. nudiflora, ao longo do seu ciclo de vida.
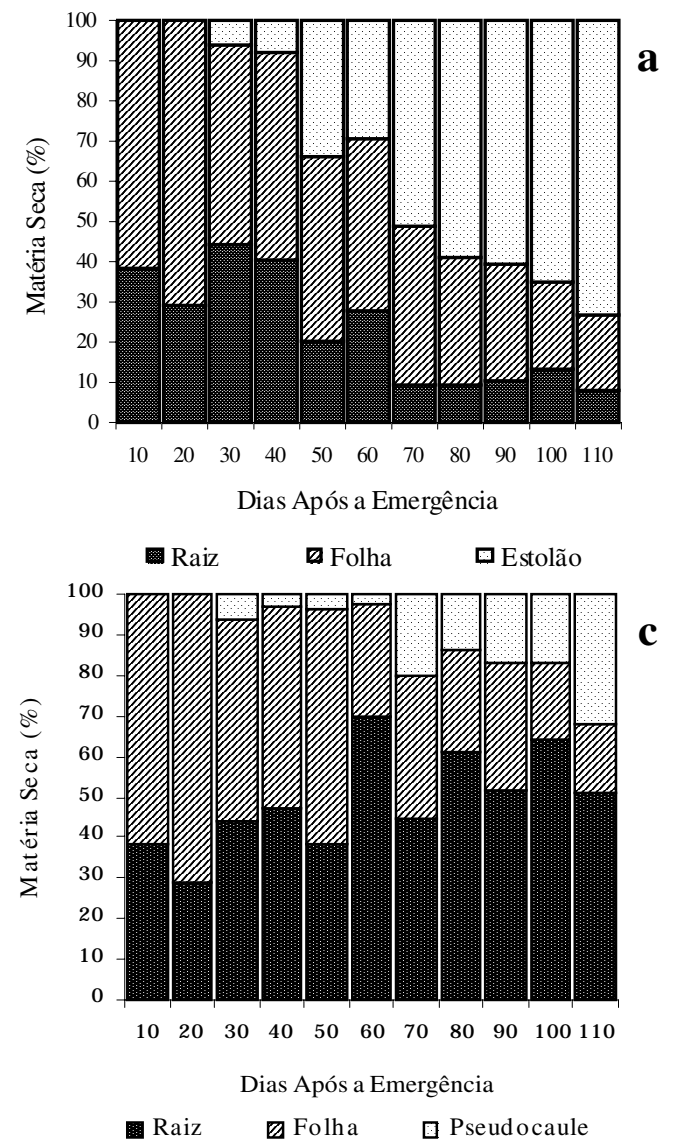

À semelhança do observado para os componentes vegetativos da planta total e da planta mãe, observou-se que o acúmulo de matéria seca nas plantas-filhas evidenciou incremento crescente até 90 DAE, com tendência à

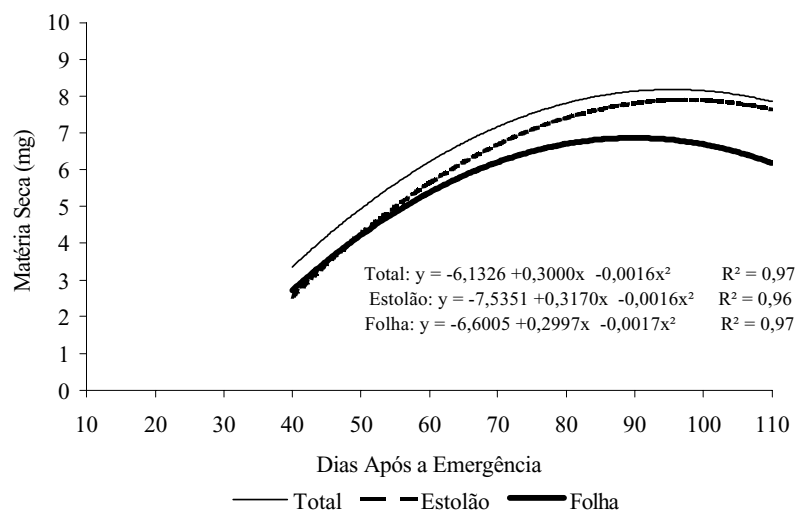

Figura 4 - Acúmulo de matéria seca nos diferentes componentes vegetativos das plantas-filhas de $M$. nudiflora, ao longo do seu ciclo de vida.
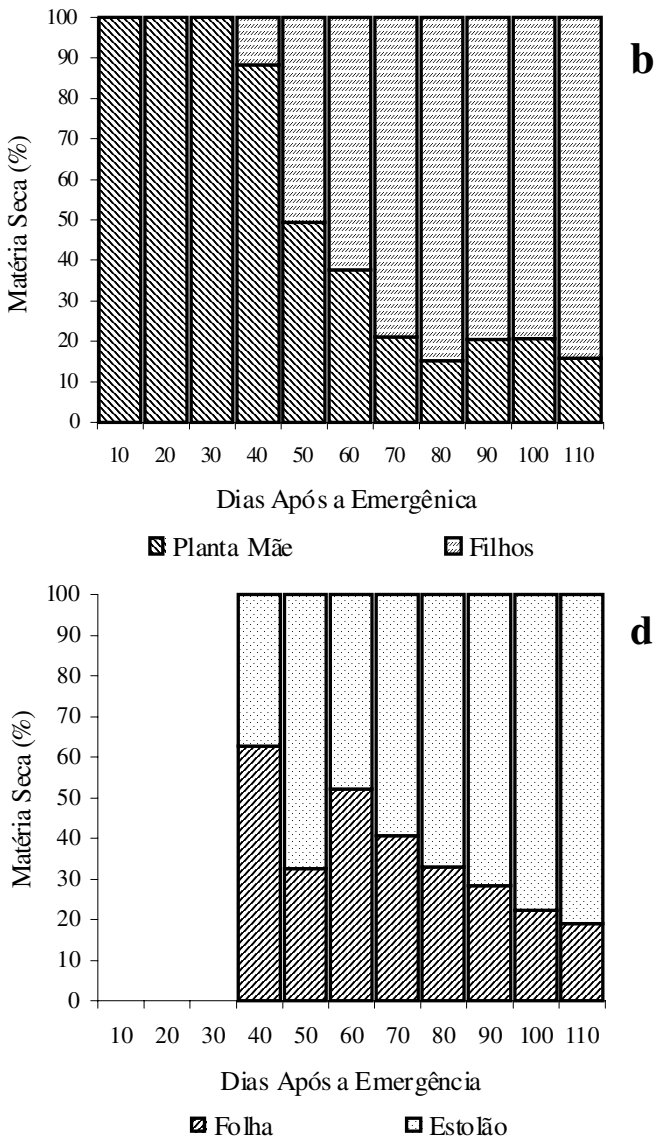

Figura 5 - Partição da matéria seca nos diferentes componentes vegetativos de $M$. nudiflora, durante seu ciclo de vida: a) matéria seca da planta, b) matéria seca total, c) matéria seca da planta-mãe e d) matéria seca das plantas-filhas. 
estabilidade após este, ajustando-se a curvas de modelo quadrático (Figura 4). Analisando a participação dos componentes vegetativos das plantas-filhas no peso total (Figura 5d), verificou-se a superioridade crescente dos estolões ao longo de todo o ciclo de vida, alcançando, em média, 71,8 e $81,1 \%$ do total de matéria seca acumulada entre 90 e $110 \mathrm{DAE}$, respectivamente.

Os resultados obtidos demonstram que as plantas de $M$. nudiflora apresentam alto potencial de desenvolvimento vegetativo e reprodutivo, característica que evidencia elevado poder de competição pelos fatores que influenciam no desenvolvimento das culturas (espaço, nutrientes e luz). Considerando os estádios de desenvolvimento das plantas de $M$. nudiflora, o momento ideal para se realizar o controle poderia se estender até a época de início da formação dos estolões e das plantasfilhas (30 DAE), de maneira a evitar os efeitos negativos da propagação vegetativa à cultura, bem como antes do florescimento, para diminuir o banco de sementes da planta daninha na área de cultivo. Mais estudos devem ser realizados, a fim de quantificar os efeitos da interferência dessa planta daninha na cultura do arroz irrigado e de identificar herbicidas para o controle de $M$. nudiflora nessa cultura.

\section{LITERATURA CITADA}

AMARAL, A. S. Controle químico de ciperáceas na cultura do arroz irrigado. Lav. Arrozeira, v. 48, n. 420, p. 3-7, 1995.

ANDRADE, V. A. Efeito da densidade de capim-arroz na produtividade de arroz irrigado. Lav. Arrozeira, v. 35, n. 335 , p. $30-32,1992$.

BARROS, L. C. G.; PORTO E. R. Efeito da profundidade da lâmina de água sobre a incidência de plantas daninhas na cultura do arroz. Planta Daninha, v. 2, n. 2, p. 69-72, 1979.

FERNANDEZ, O. A. Manejo integrado de malezas. Planta Daninha, v. 5, n. 2, p. 69-75, 1982.

KISSMANN, K. G.; GROTH, D. Plantas infestantes e nocivas. 2.ed. São Paulo. BASF, 1997. Tomo 1. 110 p.

LUCCHESI, A. A. Utilização prática da análise de crescimento vegetal. AM. ESALQ. v. 41, p. 181-202, 1984.

PITELLI, R. A. Interferência de plantas daninhas em culturas agrícolas. Inf. Agropec., v. 11, n. 129, p. 16-17, 1985 .

SMITH, R. J. Weeds of major economic importance in rice and yield losses due to weed competition. In: CONFERENCE ON WEED CONTROL IN RICE. Philipines, Los Baños, IRRI, 1983. p. 19-36. 